\title{
Moving towards strategic commissioning: Impact on Clinical Commissioning Groups as membership organisations.
}

DOI:

10.1177/1355819619842272

\section{Document Version}

Accepted author manuscript

Link to publication record in Manchester Research Explorer

Citation for published version (APA):

Warwick-Giles, L., Mcdermott, I., Checkland, K., \& Moran, V. (2019). Moving towards strategic commissioning: Impact on Clinical Commissioning Groups as membership organisations. Journal of Health Services Research and Policy. https://doi.org/10.1177/1355819619842272

\section{Published in:}

Journal of Health Services Research and Policy

\section{Citing this paper}

Please note that where the full-text provided on Manchester Research Explorer is the Author Accepted Manuscript or Proof version this may differ from the final Published version. If citing, it is advised that you check and use the publisher's definitive version.

\section{General rights}

Copyright and moral rights for the publications made accessible in the Research Explorer are retained by the authors and/or other copyright owners and it is a condition of accessing publications that users recognise and abide by the legal requirements associated with these rights.

\section{Takedown policy}

If you believe that this document breaches copyright please refer to the University of Manchester's Takedown Procedures [http://man.ac.uk/04Y6Bo] or contact uml.scholarlycommunications@manchester.ac.uk providing relevant details, so we can investigate your claim.

\section{OPEN ACCESS}




\section{Moving towards strategic commissioning: Impact on Clinical Commissioning Groups as membership organisations.}

\section{Authors}

1. Dr Lynsey Warwick-Giles, Research Associate, Health Policy, Politics \& Organisation (HiPPO), University of Manchester, United Kingdom

2. Dr Imelda McDermott, Research Fellow, Health Policy, Politics \& Organisation (HiPPO), University of Manchester, United Kingdom

3. Professor Kath Checkland, Professor of Health Policy \& Primary Care, Health Policy, Politics \& Organisation (HiPPO), University of Manchester, United Kingdom

4. Dr Valerie Moran, Luxembourg Institute of Health and Luxembourg Institute of Socio-Economic Research, Luxembourg.

\section{Corresponding author}

Dr Imelda McDermott (Imelda.mcdermott@manchester.ac.uk)

\section{Key words}

- Strategic commissioning

- Strategic purchasing

- Membership organisation 


\section{Abstract \\ Objective}

This paper aims to explore the nature of Clinical Commissioning Groups (CCGs) in England as membership organisations. Utilising the concept of meta-organisation as a lens, we discuss the impact that this organisational form might have on CCGs' ability to become 'strategic commissioners'.

\section{Methods}

We used a longitudinal qualitative approach to explore the adoption and implementation of primary care co-commissioning. The study was undertaken between May 2015 and June 2017, and included interviews with senior policy makers, analysis of policy documents, two telephone surveys, and case studies in four CCGs nationally.

\section{Results}

CCGs operate as membership organisations with closed boundary and low stratification, whereby a consensus or majority needs to be reached by members when activities impact on membership or the CCG's constitution. While CCGs should move towards a more strategic commissioning role that is focused on local priorities agreed by their members they are faced with a complex system of accountabilities and responsibilities, which makes this difficult to achieve.

\section{Conclusions}

The nature of CCGs as membership-based meta-organisations has the potential to both help and hinder CCGs in becoming strategic commissioners. The complexities in accountability and governance that the membership approach introduces, and the 
potential difficulties that CCGs face with competing meta-organisations raises questions about the future of CCGs as membership organisations. 


\section{Introduction}

Many health care systems have separated the purchaser from the provider role in health care. ${ }^{1}$ This includes the English National Health Service (NHS), which introduced the purchaser-provider split in the in the 1990s as a mechanism to improve efficiency through competition (widely referred to as 'internal market'). Numerous reforms have since focused on the purchasing and provision of health care services in the NHS. ${ }^{2}$ Internationally, there has been increasing emphasis on 'strategic purchasing' of health care, defined as a proactive approach to purchasing that involves incorporating population need alongside traditional purchasing factors such as quality and evidence. ${ }^{3}$ However, as Klasa et al. ${ }^{3}$ note, 'strategic' purchasing has remained difficult to implement, arguing that the concept was ideologically driven and unlikely to achieve the expressed goals of strategic purchasers.

In England, the Health and Social Care Act 2012 (HSCA12) created Clinical Commissioning Groups (CCGs) ${ }^{4}$ as the organisations responsible for purchasing (commonly referred to as 'commissioning') the majority of health services for their local population, including community, mental health and secondary care services. CCGs are statutory NHS bodies that are clinically-led and comprised of local general practitioner (GP) practices. ${ }^{4}$ The HSCA12 also established NHS England (NHSE), a statutory organisation responsible for overseeing CCGs. ${ }^{5}$

CCGs are constituted as 'membership' organisations' and membership is compulsory for all GP practices across the NHS; GP practices can choose which CCG they want to be a member of, however NHSE retains the ultimate power to decide whether a practice can join or change membership. ${ }^{5}$ 
Because of concerns about potential conflicts of interest, the commissioning of primary care services (medical, dental, eye health, and pharmacy) was, at least initially, the responsibility of NHSE to reduce the risk that GPs could commission services that they themselves provide if this responsibility was given to CCGs. ${ }^{6,7}$

The remit of CCGs includes assessing local needs, deciding priorities and strategies, and then purchasing services on behalf of the local population, thus encompassing many of the characteristics of 'strategic purchasing' described by Klasa et al. ${ }^{3}$ Yet, five years after their creation, current NHS policy emphasises the need for CCGs to become 'more strategic' using strategic commissioning. This involves a new approach that focuses more clearly on population need, ${ }^{8,9}$ as well as operating on a wide geographical area, using capitated budgets and focusing on outcome-based commissioning. ${ }^{8}$

This paper explores the nature of CCGs as membership organisations. Utilising the concept of 'meta-organisations' as a lens, we discuss the impact that this novel organisational form might have on CCGs' ability to become more strategic. We specifically focus on a recent development, which involved delegation of primary care commissioning from NHSE to CCGs. We begin by describing this recent development and then provide an overview of our theoretical lens of meta-organisations, its

relevance to CCGs, and a description of our methods. We present our results, using the meta-organisation lens, and conclude with a discussion of the implications of our findings for policy and practice.

\section{Expanding the role of CCGs: Primary care co-commissioning}

From April 2015, CCGs have assumed greater responsibilities for commissioning primary care services (primary care co-commissioning). This includes designing, 
monitoring, negotiating, and terminating contracts, designing local incentive schemes, making decisions on the establishment of new GP practices and approving practice mergers. ${ }^{10}$ CCGs had to consult their members before taking on this responsibility, with some CCGs asking their members to vote on this decision. ${ }^{6}$ There were three cocommissioning models that CCGs were able to take forward. These included: greater involvement which had no formal process but enabled CCGs to 'influence' primary care locally; joint commissioning whereby CCGs established joint committees with NHSE regional teams, remaining party to the decision making processes regarding primary care but the funding remaining the responsibility of NHSE and delegated commissioning whereby CCGs would take the lead on primary care commissioning and hold the responsibility for the primary care budget. As of 1st April 2018, 178 of 209 CCGs had opted for delegated co-commissioning arrangements. ${ }^{11}$

Co-commissioning is seen as an opportunity to help reduce the traditional boundaries between primary, community, and secondary care by shifting resources between sectors and so facilitating the development of a more integrated approach to service provision and a more population-focused approach in keeping with the 'strategic purchasing' concept. ${ }^{12}$

At the same time, co-commissioning provides CCGs with a dual (and possibly conflicting) role to both support and performance manage their GP membership to ensure fulfilment of contractual obligations. This provides a unique opportunity to study changes in the relationship dynamic between CCGs and their members.

\section{The concept of meta-organisation}

Meta-organisations comprise several independent organisations, often with a shared agenda and goal. However, as a member, organisations retain their own legal 
structures, identity, and motivations. ${ }^{13}$ Gulati et al. ${ }^{13}$ described them as "an organisation whose agents are themselves legally autonomous and not linked through employment relationships. Meta-organisations comprise of networks of firms or individuals not bound by authority based on employment relationships characterised by a system level goal" (p7). Meta-organisations are distinguished from other, individual-based organisations by the dynamic created by a membership model, in which the meta-organisation does not control the work of the members. ${ }^{14}$ The membership relationship is defined by its voluntary nature and alignment of the overall goal of the meta-organisation and its members. ${ }^{13}$

To encourage joint working and create a shared identity and purpose across the metaorganisation, strategies that demonstrate the needs and reputations of the membership organisations should be employed. It reinforces the meta-organisation's rationale as well as creating an environment for the membership organisations to work together. Non-contractual benefits to the membership organisations have the potential to encourage further membership engagement and exchange across the individual member organisations. There has been a suggestion that, in some cases, metaorganisations are organisations for the 'weak'. ${ }^{14}$ Well performing organisations that succeed on their own are less likely to see the benefits of joining a meta-organisation, as they do not require the non-pecuniary benefits that are on offer from joint working or collaboration.

Although not necessarily legal entities, meta-organisations do need some form of formal authority setting out how the meta-organisation will work, eligibility of membership, and benefits to the individual organisations involved. However, there is not one specific structure to follow to ensure the success of a meta-organisation. Gulati et al. ${ }^{13}$ suggest four meta-organisation types based on the type of membership 
boundaries and the level of stratification (hierarchical structures, including roles and tiers that are included within the meta-organisations) that are employed within the meta-organisation: (i) closed community (closed membership with low stratification), e.g. consortia and technical standards committees; (ii) open community (open membership with low stratification), e.g. Wikipedia and open source; (iii) extended enterprise (closed membership with high stratification), e.g. franchising networks; and (iv) managed ecosystem (open membership with high stratification), e.g. Android operating system.

A high level of stratification allows upper tiers within the meta-organisation to have more extensive decision-making rights and a greater responsibility for co-ordinating lower tiers. Operating in this manner has been found to motivate the membership and reduce confusion. In contrast, lower stratification meta-organisations adopt a more egalitarian approach, whereby every member has the same rights and activities and decision-making is made as a collective.

Membership relationships are influenced by the way in which boundaries are formed within the meta-organisation, including attracting, selecting, and retaining the membership. Gulati et al. ${ }^{13}$ suggest three main components for setting boundary arrangements for the membership, namely member selection, criteria for membership and duration and exclusivity. In an open membership, boundaries are permeable, and members can self-select whether to join the meta-organisation while in a closed membership, new members need approval to join the meta-organisation. This decision can be made between an individual architect and the new member, or it may need to be sought from the existing members. Depending on the type of meta-organisation, membership may be sought based on the skills and qualities they can contribute to the meta-organisation. Some meta-organisations insist that the membership of their 
meta-organisation is exclusive. Such a position is often adopted in a competitive environment to ensure that membership contributions that are required for the metaorganisation to succeed are not being offered to competing organisations.

\section{Methods}

We used a longitudinal qualitative approach to explore the adoption and implementation of primary care co-commissioning (May 2015-June 2017). Our study included several steps.

First, we identified the 'programme theories' ${ }^{15}$ underlying the introduction of primary care co-commissioning by carrying out a small number of face-to-face interviews ( $n=6)$ with senior Department of Health and NHSE staff (June-July 2015) who had played a role in the development of the co-commissioning policy. We also undertook an indepth content analysis of the main policy documents.

Second, we explored the uptake of primary care co-commissioning nationally (AprilMay 2015) by reviewing CCGs' application documents ( $n=147$ applications from 150 CCGs). We also carried out two telephone surveys from a sample of CCGs: survey 1 $(n=49)$ between June-August 2015 and survey $2(n=12)$ between August-October 2016. Our sampling criteria included; level of co-commissioning responsibility, regional team the CCG belonged to, size of CCG, urban vs rural CCG, and those undertaking collaborative commissioning with neighbouring CCG or having submitted a joint application. We interviewed CCG Board members and our survey questions focused on CCGs' experiences, problems encountered, and factors facilitating or inhibiting their development as they were undertaking the process of moving to primary care cocommissioning, and whether the CCG had realised any benefits from the new responsibility. 
Third, we conducted case studies of four CCGs nationally (January 2016-April 2017), selected based on geographical location, population size and number of GP practices (see table 1).

Table 1: Site characteristics

\begin{tabular}{|c|c|c|c|c|}
\hline & Site 1 & Site 2 & Site 3 & Site 4 \\
\hline Region & North & $\begin{array}{l}\text { Midlands \& } \\
\text { East }\end{array}$ & South & North \\
\hline Population & $\begin{array}{l}\text { Over } 40 \\
\text { practices with } \\
\text { an approx. } \\
\text { population of } \\
350 \mathrm{k}\end{array}$ & $\begin{array}{l}\text { Over } 100 \\
\text { practices with } \\
\text { an approx. } \\
\text { population of } \\
550 \mathrm{k}\end{array}$ & $\begin{array}{l}\text { Over } 20 \\
\text { practices with } \\
\text { an approx. } \\
\text { population of } \\
150 \mathrm{k}\end{array}$ & $\begin{array}{l}\text { Over } 40 \\
\text { practices with an } \\
\text { approx. } \\
\text { population of } \\
250 \mathrm{k}\end{array}$ \\
\hline GP Federation & Yes & Yes & No & Yes \\
\hline
\end{tabular}

We explored the practice of co-commissioning and how this affected the internal structure and functioning of the CCG (including the relationship with member practices), external relationships, and the factors that facilitated or inhibited the development of new services. We observed 74 meetings (see table 2) associated with co-commissioning (i.e. co-commissioning committees, finance and contracting meetings) and conducted 42 face-to-face interviews with members of cocommissioning committees including GPs, lay members, quality and contracting staff. We analysed the data using thematic analysis. 
Table 2: Data collected between January 2016 and April 2017

\begin{tabular}{|l|l|l|l|l|l|}
\hline & Site 1 & Site 2 & Site 3 & Site 4 & Total \\
\hline $\begin{array}{l}\text { Meeting } \\
\text { attendance }\end{array}$ & 13 & 24 & 6 & 31 & 74 (approx. \\
111 hours of \\
observations)
\end{tabular}

\section{Results}

In the results section we focus on the data that was collected during the case study phase of the project. Discussing how a CCG can be identified as a meta-organisation, the challenges that CCGs face with competing accountabilities to organisations beyond their membership and the changing relationship between CCGs and their members because of co-commissioning.

\section{CCGs as meta-organisations}

When CCGs were in their infancy, CCGs were tasked with engaging with their member practices, whose insight and local knowledge of patients was perceived to add value and offer insight into patient experience, health needs and how services could be developed more efficiently ${ }^{12}$. The potential success of CCG plans and delivery against their outcomes was understood to be underpinned by the engagement of member practices and the introduction of the clinical voice. The General Practitioners Committee, which represents all GPs in the UK in contractual negotiations, published 
guidance setting out what should be included in each CCG constitution. ${ }^{16}$ Our analysis of CCG constitutions in our case study sites found that they were all very similar, despite the rhetorical appeal to 'localness' in national policy documents.

CCG constitutions were in keeping with our identification of CCGs as metaorganisations. The vision and goals of the CCG as a membership organisation were decided by the CCG and its members, demonstrating a joint agenda. ${ }^{14}$ CCGs comprise GP practices, which are individual businesses providing primary care services. All of the constitutions examined stipulated that CCGs are formed within a specific geographical area this correlates with what we described earlier as a closed boundary definition of membership. ${ }^{13}$

The geographical area and contract specific terms set out in individual CCGs' constitutions provide commonalities and exclusivity of membership to develop a metaorganisation. CCGs have a closed membership whereby GP practices may only be a member of one CCG. However, GP practices can be members of other 'types' of metaorganisations, for example other provider networks such as GP Federations (a mechanism allowing a number of GP practices to come together to form a collaboration). The reviewed constitutions did not clearly define the actual meaning of membership. Instead, they provided a list of all GP practice members. They did, however, document the formalities of the application for and cessation of membership and dispute resolution.

Using Gulati et al's. ${ }^{13}$ typology of meta-organisations, we argue that CCGs with their GP practice membership are operating as a closed community (closed membership with low stratification). CCGs operate as a consortia or standards committee whereby a consensus or majority needs to be reached by GP members when activities will impact the membership or the constitution. For example, when co-commissioning was 
introduced in 2014, CCGs were only able to take on the responsibility if their GP membership had agreed to the change. The closed membership model adopted by CCGs has allowed variation between how CCGs construct themselves, with some CCGs having a two-tier structure, including a high-level board and GP membership, whereas others employed a locality model, dividing the CCG into geographical areas and developing a more layered and hierarchical structure.

\section{CCG competing responsibilities}

An assessment of the early workings of CCGs found that they had had the opportunity to involve and work with their members ${ }^{17}$ However, in our analysis, decisions and actions were found to have become distanced from the membership as CCGs evolved, because of the requirement to respond to national directives within tight deadlines. One of our respondents in an interview spoke of the frustration that they had experienced with the extensive number of 'must do' directions that CCGs had received from NHSE.

Rather than being an autonomous organisation, discussing plans with their membership and facing local challenges, the CCG was essentially enacting national policy, which led to a deterioration in the CCG's relationship with the membership

This need to respond to national rather than local priorities goes against the principles of a strong meta-organisation. Solansky et al. ${ }^{18}$ found that meta-organisations experienced de-stabilising tensions based on three factors: unstable membership; disordered structures; and diverse organisational contexts. In the context of CCGs, the diverse organisational contexts and the different responsibilities that CCGs and GPs face, combined with priorities and responsibilities set by NHSE, appeared to cause de-stabilising tensions between the CCG and its membership 
One of the key obligations of CCGs is to reach financial balance at the end of every financial year. This requirement was of concern to GP members in one of our case study sites, who perceived that it meant that money earmarked for primary care development was diverted to reduce an overspend on secondary care services:

GP representative: Obviously we have not seen this before because it was with NHSE. We should use this opportunity to reinvest it into primary care.

CCG Chief Officer: We will do that next year [...].

GP representative: Why not now?

CCG Chief Officer: Because we have [...] overspend that we need to reduce. We are not throwing money at primary care that is not on the books and which will not help deliver the reduction of spend.

$[\ldots .$.

GP representative: Year on year we prop up secondary care with additional funding but not primary care.

\section{$[\ldots]$}

CCG Chair: I can assure you we did not plan to underspend on primary care. Next year we have plenty of plans to invest in primary care. The plan has always been the shift towards primary care. [Governing Body meeting November 2016, M54]

Thus, although the GP representative spoke of their concern about the decisions made, the CCG governing body decided that it was more important for the CCG to remain financially stable to adhere to national rules, rather than change their approach to reflect their membership. 


\section{Upward vs downward accountabilities}

The HSCA12 clearly defined the roles and responsibilities, which CCGs and NHSE have with respect to GP practices. Unlike most meta-organisations, many aspects of CCGs' role are controlled and monitored centrally, that is by NHSE. ${ }^{19}$ As highlighted earlier, CCGs do not have the sole power to make decisions about eligible members; NHSE must approve membership changes. This strong line of accountability between a CCG and NHSE has a potential impact on the CCG's relationship with its members. For example, if GP practices wish to merge, and the CCG governing body and membership all agree that it is in the best interests of the local population, NHSE could still decline to sanction the change. This illustrates an important point about metaorganisations; namely that difficulties may arise when the formal accountabilities of member organisations and of the meta-organisation as a whole differ. ${ }^{20}$ In this context, GP practice representatives are accountable to both the meta-organisation and their respective employing organisations, whereas a CCGs' primary accountability is to NHSE. ${ }^{21}$. This raises significant issues for CCGs, who may be unable to fulfil the wishes of their members.

The distant relationship and opaque lines of accountability between local GP practices and NHSE provided each CCG and their membership with an opportunity in the context of co-commissioning. Such new opportunities within meta-organisations can be seen as having the potential to stabilise tensions and to energise the membership ${ }^{18,22}$, such as providing opportunity to overcome some of the issues that CCGs and general practice had faced since the HSCA12. CCG leaders argued that this would improve the CCG's relations with their membership. However, a changing membership dynamic may have a detrimental effect. Co-commissioning has caused increased concerns over conflicts of interest, whereby GPs could commission services 
that they themselves provide. ${ }^{23}$ This has led to GP board members in one of our case study CCGs being asked to leave the room or abstaining from voting when decisions about primary medical services are made. This meant the CCG made clinically-related decisions without any clinical input:

It was a major contract, which had to be approved by Governing Body, however, all of the GPs there, or themselves, provide minor surgery for our patients, and therefore, we were all directly conflicted. What happened was, that in fact at that stage, almost to be seen to be cleaner than clean, all the GPs left the room. [...] The problem was, it was then taken over that there were no clinicians left in the room. [GP ID17]

Curtailing the membership voice and local knowledge in this way may alienate the GP membership and fracture the shared identity that CCGs and their members have worked hard to develop, causing further de-stabilising tensions.

\section{Support versus performance management of membership}

A further consequence of CCGs taking on co-commissioning was the changing relationship dynamic that being a commissioner of the GP membership introduces. In addition to supporting their GP membership, CCGs also had to performance manage them to ensure fulfilment of contractual obligations. The impact of this on CCGmembership relationships is not yet clear. At the time of data collection, our sites were undertaking this responsibility for just over one year and were still trying to understand the contractual and financial elements of the system. However, it was evident that this fundamental relationship change had potential to disrupt and alter the CCG relationship with its members, with the supportive role becoming less apparent over 
time. Some of our respondents highlighted how this change had increased tensions between the CCG and its members

It's not been without its challenges, and being a membership organisation, where GPs felt that we were working together, then suddenly you're performance managing them around their contracts [...] I think the relationships and the partnership issue has been a challenge for the CCG personally. [Manager ID20]

Thus, the requirement for CCGs to performance manage their GP members changed the balance of power between the CCG and GP membership. As noted, GP practices must be a member of a CCG, but it is not clear whether NHSE will allow a practice to leave CCG on grounds that they disagree with the approach taken to performance management or because they object to the changing relationship dynamic. However, practices could question the CCG Chair or reduce their engagement with the CCG by, for example, only doing the bare minimum that is required of them as a member (as set out in the constitution).

Aware of the changing relationship dynamic between the CCG and the GP membership, one of our case study sites acknowledged that the co-commissioning responsibility needed to be separated from the supportive membership role that the CCG originally provided, that is, trying to stabilise the tensions ${ }^{18}$ that were being faced in the meta-organisation. However, at the time of data collection no firm plans had been in place to try and ensure the CCG maintained a supportive relationship with the GP membership.

\section{Discussion}


The role of CCGs is changing, with a more strategic purchasing role being prescribed to complement a changing policy landscape that supports cooperation rather than competition. Klasa et al. ${ }^{3}$ identify five core elements of strategic purchasing: addressing population health needs; empowering citizens; strengthening government stewardship and capacity developing effective purchaser and provider organisations; and cost-effective contracting. Strategic commissioning as described here mirrors these characteristics, with a focus on empowering citizens and addressing population needs.

We highlighted earlier that the idea of strategic purchasing can be seen to be driven by ideology, but, as noted by Klasa et al. $^{3}$, there are specific components that can provide benefits to health systems. They argued that policymakers should attempt to create "powerful, separate purchasers with the legal position, data, and economic power to make purchasing strategic" (p.16). The creation of CCGs was intended to achieve that precise objective. The delegation of primary care commissioning responsibilities from NHSE to CCGs with a more population-focused approach is also in keeping with the strategic purchasing concept. However, within the English context, as the government retains control of financial flows, this prevented the implementation of local agendas, in turn reflecting Klasa et al.'s observation that who holds the funding and controls the financing of the system plays an important role in determining whether a strategic approach to purchasing is possible. ${ }^{3}$

Our study suggests that a move towards strategic commissioning presents numerous challenges not only in terms of increasing complexity in horizontal accountability but also what it means to be a membership organisation (and which organisations). The nature of CCGs as membership-based meta-organisations has the potential to both help and hinder CCGs in becoming strategic commissioners. The key focus is on 
addressing population health needs ${ }^{3}$, which requires services to be commissioned over larger geographical areas which will include multiple CCGs and additional organisations. This requires CCGs to form a joint commissioning arrangements which requires a formal vote from CCG members and can have an impact on CCG constitutions ${ }^{25}$.. The integration of health and social care raises further concerns about the erosion of clinical leadership in commissioning and the challenges arising from different accountability structures. ${ }^{26}$ The integration of health and social care brings together organisations with different working practices and adds the element of local democracy into decision making through the local authority, It may be that, if the current rhetorical commitment to a more strategic approach to commissioning is maintained, the membership organisation concept might be revisited.

CCG constitutions make accountability to members clear, but it is conceivable that the interests of GP members' and local populations may diverge. The majority of CCGs struggle to engage GPs in commissioning ${ }^{24}$ and many GPs preferring to be involved in provider organisations such as GP Federations. Federations ${ }^{12}$ can thus be seen as competing meta-organisations. The meta-organisation literature suggests that strong meta-organisations that better reflect the needs of their members and offer them support or business are likely to have more engagement from members. This may be the case for GP Federations, which have the single purpose of developing and strengthening primary care providers. Conversely, CCGs, as strategic commissioners have wide-ranging responsibilities, which may conflict with their role as membership organisations and weaken the meta-organisation model.

In this paper we have explored what it means for CCGs to be strategic commissioners, which have characteristics that mirror strategic purchasers internationally. The organisation of CCGs as membership organisations created roles that may conflict 
with their role as strategic commissioners. We have highlighted the complexities in accountability and governance that the membership approach introduces, and the potential difficulties of having competing meta-organisations which potentially offers a more attractive membership model. Taken together, this suggests that it may be timely to revisit the concept of a CCG as a membership organisation. 


\section{References}

1. Figueras J, Robinson R, Jakubowski E. Purchasing to improve health systems performance (Eds)., 2005.

2. Maynard A, Dixon M. Should the NHS abolish the purchaser-provider split? BMJ Online 2016; 354. DOI: 10.1136/bmj.i3825.

3. Klasa K, Greer SL, van Ginneken E. Strategic Purchasing in Practice:

Comparing Ten European Countries. New York: Health Policy, 2018; 122: 457-472.

4. Department of Health. Equity and excellence: liberating the NHS. White Paper, 2010.

5. NHS England. CCG improvement and assessment framework 2016/17 2016.

6. McDermott I, Checkland K, Warwick-Giles L, et al. Understanding primary care co-commissioning: Uptake, scope of activity and process of change. Interim report. Manchester, 2016.

7. McDermott I, Checkland K, Coleman A. Primary care co-commissioning:

Challenges faced by clinical commissioning groups in England. Br J Gen Pract 2018; 68.

8. NHS Clinical Commissioners. Making strategic commissioning work: Lessons from home and away. 2017.

9. Simon J. The Changing Commissioning Landscape.2017.

10. NHS England. Next steps towards primary care co-commissioning. 2014.

11. NHS England. Clinical Commissioning Groups (CCGs) with delegated and joint arrangements as of 1 April 2018. 2018; 1-6. 
12. NHS England. Five Year Forward View. 2014.

13. Gulati R, Puranam P, Tushman M. Meta-organization Design: Rethinking design in interorganizational and community contexts. Strateg Manag J 2012; 33: $571-586$.

14. Ahrne G, Brunsson N. Organizations and meta-organizations. Scand J Manag 2005; 21: 429-449.

15. Weiss $\mathrm{CH}$. Theory-Based Evaluation: Past, Present, and Future. New Dir Eval $2007 ; 68-81$.

16. General Practitioners Committee. Clinical Commissioning Groups Constitutions.

17. Checkland K, Coleman A, Segar J, et al. Exploring the early workings of emerging Clinical Commissioning Groups. Final report. (2012).

18. Solansky, S. T, Beck, T. E, Travis D. A complexity perspective of a metaorganization team: The role of destabilizing and stabilizing tensions. Hum Relations 2014; 1007-1033.

19. Checkland K, Dam R, HAMMOND J, et al. Being Autonomous and Having Space in which to Act: Commissioning in the 'New NHS' in England. J Soc Policy 2017; 190: 1-19.

20. Bor S. A theory of meta-organization: An analysis of steering processes in European Commission-funded R \& D. 'Network of Excellence' consortia. PhD Thesis, Helinski, 2014.

21. Berkowitz H, Bor S. Why Meta-Organizations Matter: A Response to Lawton et al and Spillman. J Manag Inq 2018; 1-8. 
22. Hackman J. Leading Teams: Setting the Stage for Great Performances. Boston: Harvard Business School Press, 2002.

23. Moran $\mathrm{V}$, Allen $\mathrm{P}, \mathrm{McDermott} \mathrm{I}$, et al. How are clinical commissioning groups managing conflicts of interest under primary care co-commissioning in England? : a qualitative analysis. BMJ Open 2017; 7.

24. McDermott I, Checkland K, Coleman A, et al. Engaging GPs in commissioning: realist evaluation of the early experiences of Clinical Commissioning Groups in the English NHS. J Health Serv Res Policy 2016; 22: 4-11.

25. McDermott I, Warwick-Giles L, Gore O, et al. Understanding Primary Care CoCommissioning: Uptake, Development, and Impacts. Final Report. Manchester, 2017.

26. Moran V, Allen P, McDermott I. Investigating recent developments in the commissioning system. Final Report. London, 2018. 